\title{
EVALUATION OF DIELECTRIC STRENGTH OF EPDM ELASTOMER LOADED WITH ATH FILLER
}

\author{
Tamer Sheta ${ }^{1} \mathbb{}$, A.Hossam Gad 2, L.S. Nasrat ${ }^{3}$, S.M. El-Debeiky 4 \\ 1,2,4 Electrical Power and Machines Eng. Dept, Ain-Shams University, Egypt \\ ${ }^{3}$ Electrical Power and Machines Eng. Dept, Aswan University, Egypt
}

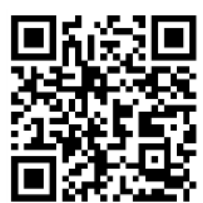

DOI: https://doi.org/10.29121/IJOEST.v4.i3.2020.82

Article Type: Research Article

Article Citation: Tamer Sheta, A.Hossam Gad, L.S. Nasrat, and S.M. El-Debeiky. (2020). EVALUATION

OF DIELECTRIC STRENGTH OF EPDM ELASTOMER LOADED WITH ATH FILLER. International Journal of Engineering Science Technologies, 4(3), 13-18. https://doi.org/10.29121/IJOEST.v 4.i3.2020.82

Received Date: 28 April 2020

Accepted Date: 18 May 2020

Keywords:

EPDM Elastomer

ATH Filler

Dielectric Breakdown Strength

Thermal Aging

\section{ABSTRACT}

Ethylene Propylene Diene Monomer (EPDM) electrical properties are improved by adding Alumina Trihydrate (ATH) filler. Composite of EPDM with ATH filler are prepared with 10\%, 20\%, 30\% and 40\% percentages of concentration. The dielectric strength of the composite samples are tested under various thermal conditions such as $(25,70,100$ and 130$){ }^{\circ} \mathrm{C}$ to simulate the various types of climates and clarify the effect of high temperature on the electrical properties of elastomers. Composite samples were exposed also to different climate conditions such as wet and salt. The obtained results of the composite performance are analyzed and discussed in the light of the variations of the material microscopic structure.

\section{INTRODUCTION}

Insulating materials made from porcelain have more than a century of service, while insulating materials made from polymers have only several decades. Nowadays the usage of polymers has been increasing every time due to the enormous advantages of polymers over porcelain and ceramics such as follows:

Breakage, Ceramics are very fragile; this means that ceramics can be broken easily in transit, handling or installation.

Weight, Porcelain bodies are very massive due to the dense nature of ceramics, which lead to difficulty in handling and transportation, especially on replacement during maintenance and repairs in addition to high cost [1].

The usage of polymers insulators began since 1940s when organic insulators materials were used to product high voltage electrical insulators from epoxy resins. The insulators made from polymers material became applicable to use for outdoor insulators in 1950s because of alumina trihydrate filler that participated in increasing the tracking and erosion resistance of polymers. The real use of polymers was in 1960s and 1970s when many researches were

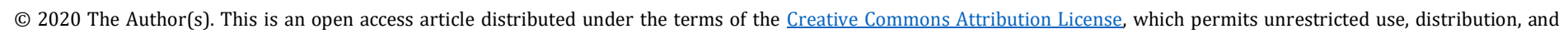
reproduction in any medium, provided the original author and source are credited. 
made to develop the polymers. Finally, the wide use of polymers started in 1980s [2]. Recently, polymer composites are used as high voltage insulation materials. Silicone rubber is better than EPDM rubber in weather resistance. However, it was found that by adding carbon black to EPDM rubber has resulted in a good weathering property of EPDM rubber without any degradation of tracking resistance. The electrical tracking resistance of EPDM rubber will be better by adding fillers like Alumina trihydrates (ATH) [3], [4].

One of the most substantial factors that lead the cables to be aged is increasing the temperature over cables insulation. The ampacity of the conductor to carry a current is restricted by maximum operating temperature, because of the insulation of cables is

prematurely aged if thermally Overstressed. It is very important to define the temperature distribution in the dielectric material of the power cable and in the surrounding soil.

The mechanical properties of insulation have been investigated by applying mechanical stress to the sample until break. Elongation test were applied to the sample to illustrate the mechanical properties.

Many reasons can be found to substantiate the goals for adding fillers. Apart from reducing material cost, the most important reason of fillers is to reinforce the physical, mechanical and electrical properties. Three of the main characteristics of fillers to enhance the polymer matrix are: the particle shape, the polymer-filler bonding capability, and the particle size. The size of the particles is directly proportional to surface area of the particles; consequently, the interaction between the particles and polymer matrix becomes very influential when the particles become very small [5].

The present research has been carried out to investigate how to improve the electrical, physical and mechanical properties of EPDM composites by adding different percentages of ATH filler under various operating conditions. Thus, prepared samples have been tested under different atmospheric conditions.

\section{TESTED SPECIMENS}

Many samples with different percentages of ATH filler were prepared. Table (1) presents the samples sheets mixes from EPDM with different amount of ATH filler. Five composites have been prepared without, with $10 \%$, with $20 \%$, with $30 \%$ and with $40 \%$ of ATH filler.

The ATH filler is added to investigate how it enhances the mechanical, electrical and physical properties of EPDM composites by changing its chemical formulation, in order to withstand different conditions.

Samples were prepared in the form of discs with $5 \mathrm{~cm}$ diameter and $1 \mathrm{~mm}$ thickness as shown in Figure (1)

Table 1: Tested Samples Mixes.

\begin{tabular}{|c|c|c|}
\hline Blend symbol & ATH $\%$ & EPDM $\%$ \\
\hline A & 0 & $100 \%$ \\
\hline B & $10 \%$ & $90 \%$ \\
\hline C & $20 \%$ & $80 \%$ \\
\hline D & $30 \%$ & $70 \%$ \\
\hline E & $40 \%$ & $60 \%$ \\
\hline
\end{tabular}

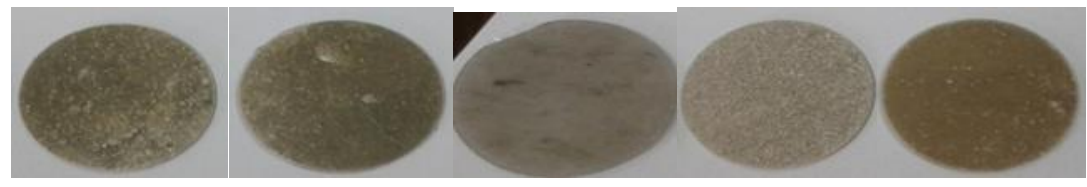

(A)

(B)

(C)

(D)

(E)

Figure 1: Different types of composite samples. 


\section{EXPERIMENTAL TESTS}

The test circuit contained a variable power transformer $(100 \mathrm{kV}-5 \mathrm{kVA})$. A resistor of $5 \mathrm{M} \Omega$ should be connected in series with the secondary coil of the transformer to limit the current. The sample was placed between two electrodes which connected directly to the transformer. The high voltage circuit should be placed in an earthed cage. The output of the transformer is gradually increased until breakdown occurs, all results had been recorded, repeated and the average were taken. The dielectric strength for the specimen was taken according to ASTM D149. Specimens have been immersed in tap water for $24 \mathrm{~h}$, and then were tested using ac voltages. To investigate the impact of adding some contaminant other specimens have been sunken in $5 \% \mathrm{NaCl}$ solution for the same period (24 h). Dust over the samples should be removed by cleaning them well by using distilled water prior to the test [6].

The tensile strength is a kind of the mechanical test to evaluate the ability of the samples to withstand the mechanical force. The mechanical features of the samples were observed according to ASTM D412. Three samples are used for each composition. The dimension of the sample is $1 \mathrm{~mm}$ thickness and $5 \mathrm{~cm}$ in length has a dumbbell shape as in Figure (2).From the two ends the sample is clamped then the machine is running with cross speed of $50 \mathrm{~mm} / \mathrm{min}$ until break, then the tensile strength was measured in (MPa) [7].

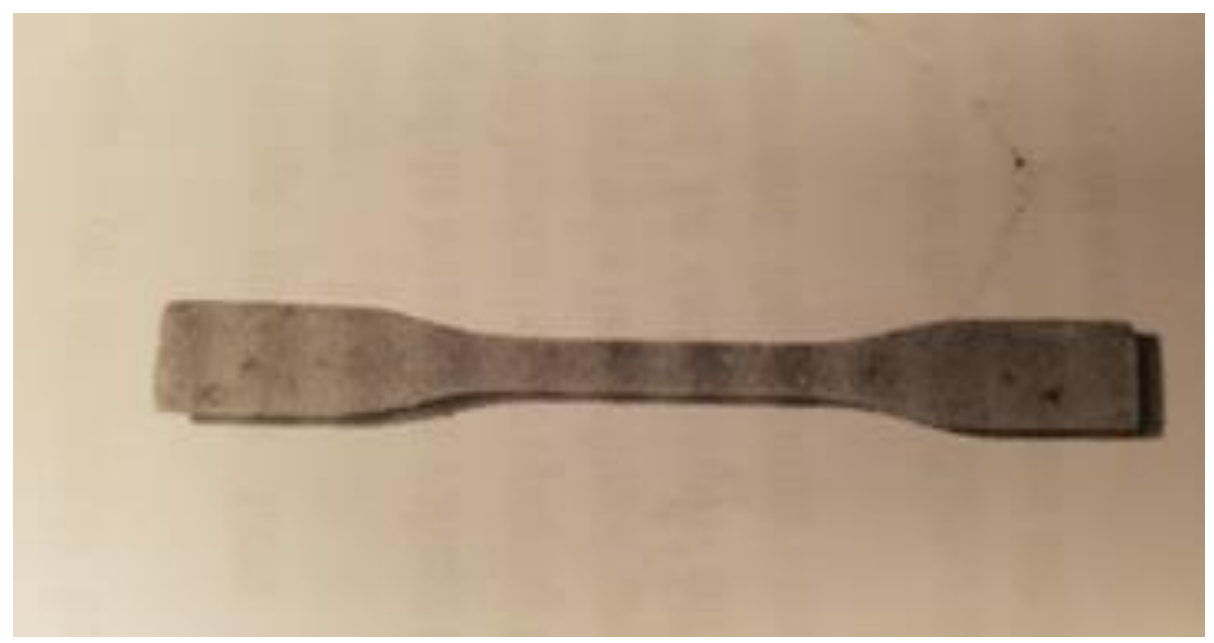

Figure 2: The structure of samples used for Mechanical test.

\section{Results, Analysis and Discussion}

\subsection{DIELECTRIC STRENGTH OF EPDM COMPOSITES}

Figure (3) represents the results of the breakdown test for the five composites of EPDM with different ATH filler percentages. At $25^{\circ} \mathrm{C}$, the recorded value is $30 \mathrm{kV} / \mathrm{mm}$ while at $130^{\circ} \mathrm{C}$, the recorded value is $26 \mathrm{kV} / \mathrm{mm}$ for blend composite. By increasing the temperature over the EPDM composites as shown in Figure (3), one can notice that the break down voltage decreases. By adding ATH filler the break down voltage improved until it reaches to its maximum at $30 \%$ ATH percentage where It recorded $32.5 \mathrm{kV} / \mathrm{mm}$ at $130^{\circ} \mathrm{C}$, while it has recorded $37 \mathrm{kV} / \mathrm{mm}$ at $25^{\circ} \mathrm{C}$. Increasing the ATH percentage over 30\% BDV decreases. This can be ascribed to the increased composite absorption to water because of the ATH properties. Thus, the breakdown voltage for EPDM composite insulators increases by increasing ATH filler percentages up to $30 \%$ then decreases. 


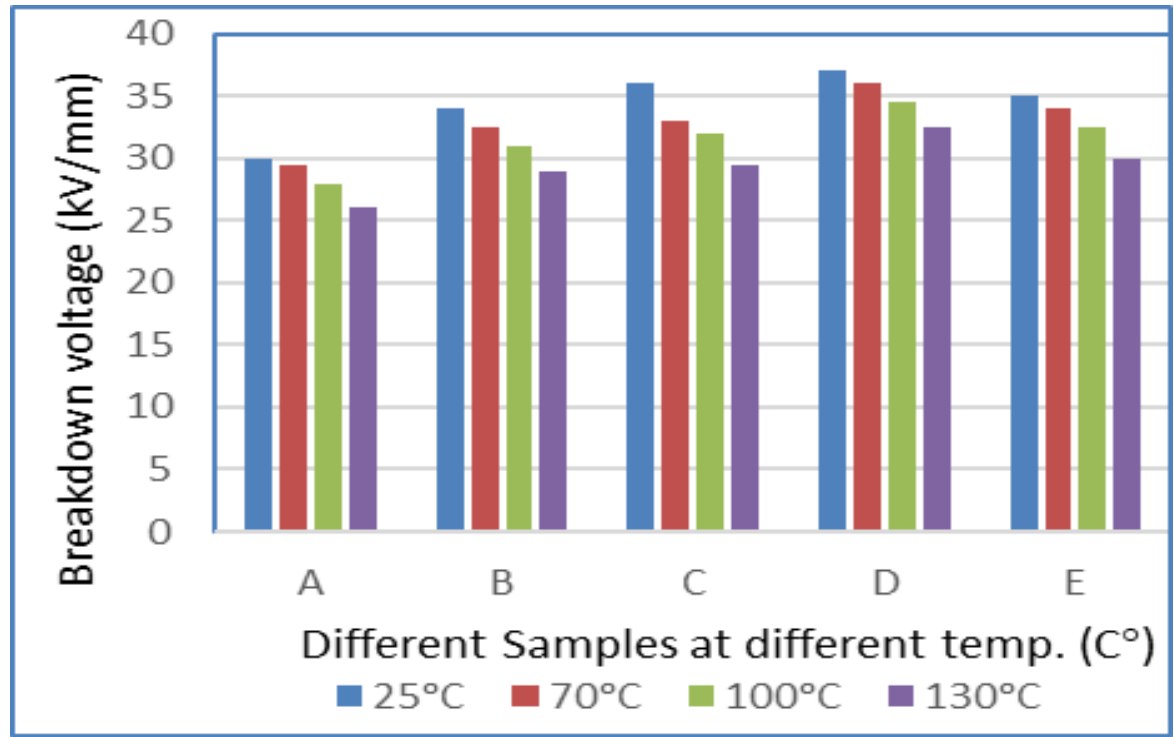

Figure 3: The effect of temperature on the breakdown voltage for different EPDM/ATH composites.

Further, the dielectric strength results of EPDM composites with different ATH filler percentage under wet and salt conditions are shown in Fig (4). At blend composites the BDV recorded $27 \mathrm{kV} / \mathrm{mm}$ and $24 \mathrm{kV} / \mathrm{mm}$ respectively at wet and salt conditions, while it recorded $30 \mathrm{kV} / \mathrm{mm}$ at the dry condition. This illustrates the main effect of contaminated condition in decreasing the BDV. By adding ATH the BDV will improve until it reaches to its maximum at $30 \%$ of ATH added to EPDM recording $34 \mathrm{kV} / \mathrm{mm}$ and $32.5 \mathrm{kV} / \mathrm{mm}$ at wet and salt conditions respectively. This means that the BDV is enhanced by almost $26 \%$ for wet condition and by $35 \%$ for salt conditions. Therefore, one can conclude that the best percentage of ATH filler is 30\% to give high breakdown voltages for EPDM/ATH composite, i.e. the breakdown voltage for EPDM increases gradually by increasing the filler percentage up to $30 \%$ at different conditions which are simulated by salt and wet.

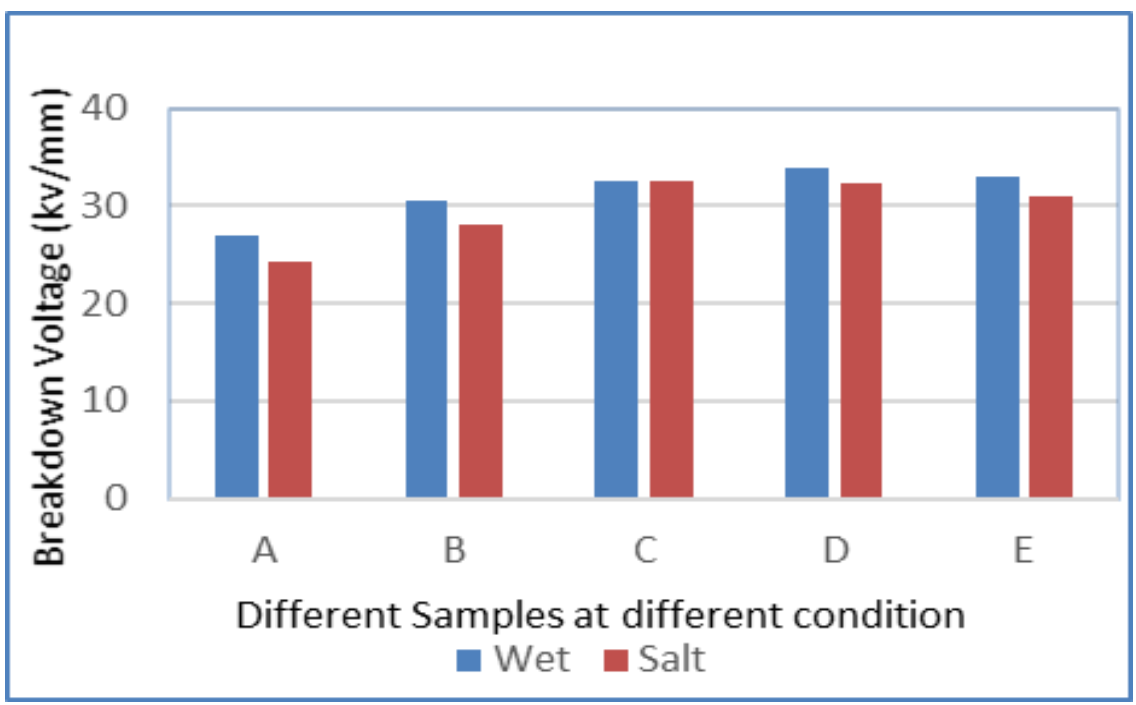

Figure 4: The effect of wet and salt conditions on the breakdown voltage for different EPDM/ATH composite.

Thus, the above results show that the presence of water droplets over the surface of the insulator improves the electric field intensity distribution and this causes the electrical breakdown to increase. Water drops on the surface of the insulators were found to vibrate in many ways and were moved away from the high electric stress zones to low electric stress zones. Drops of water on the surface of the polymer grow larger by absorbing droplets of water from the fog or by coalescing together [8]. 
EPDM composite under salinity conditions are more sensitive than wet and dry conditions. The breakdown voltage (BDV) of composite insulator is decreasing due to the absorption of composite material to salt solution. Immersion in $\mathrm{NaCl}$ solution resulted in further drop in the insulation properties, probably due to hydrolysis of $\mathrm{NaCl}$ resulting in the formation of $\mathrm{NaOH}$ and evolution of $\mathrm{HCl}$ gas which further dissolves in water.

Further, in this respect, the authors believe that the composite insulation with a high percentage of ATH filler of $30 \%$ can form a surface resistance stack keeping a uniform voltage distribution or quasi-uniform field under the voltage stress, thus increasing the breakdown voltage. The surface wet due to water or humidity can have the same effect. With further increase of the filler parentage and/or the surface wet or pollution, a more conductivity path can form decreasing the breakdown voltage.

\subsection{MECHANICAL PROPERTIES OF EPDM COMPOSITES}

Figure (5) illustrates the effect of increasing ATH loading on the tensile strength of EPDM/ATH composites. Table (2) shows the tensile strength at different filler percentages. It recorded $1.66 \mathrm{MPa}$ for blend sample while it recorded $2.93 \mathrm{MPa}$ for $20 \%$ of ATH, this means that the mechanical stress improved by $76.5 \%$. By increasing the filler, the mechanical stress will decrease recording $2.43 \mathrm{MPa}$ at $30 \%$ of ATH and $1.76 \mathrm{MPa}$ at $40 \%$ of ATH.

Table 2: Average results for tensile strength.

\begin{tabular}{|c|c|c|c|c|c|c|}
\hline \multicolumn{2}{|c|}{ SAMPLES } & A & B & $\mathrm{C}$ & $\mathrm{D}$ & $E$ \\
\hline \multicolumn{2}{|c|}{ EPDM \% } & 100 & 90 & 80 & 70 & 60 \\
\hline \multicolumn{2}{|c|}{ ATH \% } & 0 & 10 & 20 & 30 & 40 \\
\hline 1 & \multirow[t]{3}{*}{ Tensile Strength (MPa) } & 1.8 & 1.9 & 2.7 & 2.4 & 2.0 \\
\hline 2 & & 1.7 & 2.2 & 3.0 & 2.3 & 1.6 \\
\hline 3 & & 1.5 & 2.3 & 3.1 & 2.6 & 1.7 \\
\hline \multicolumn{2}{|c|}{ Average Tensile Strength } & 1.66 & 2.13 & 2.93 & 2.43 & 1.76 \\
\hline
\end{tabular}

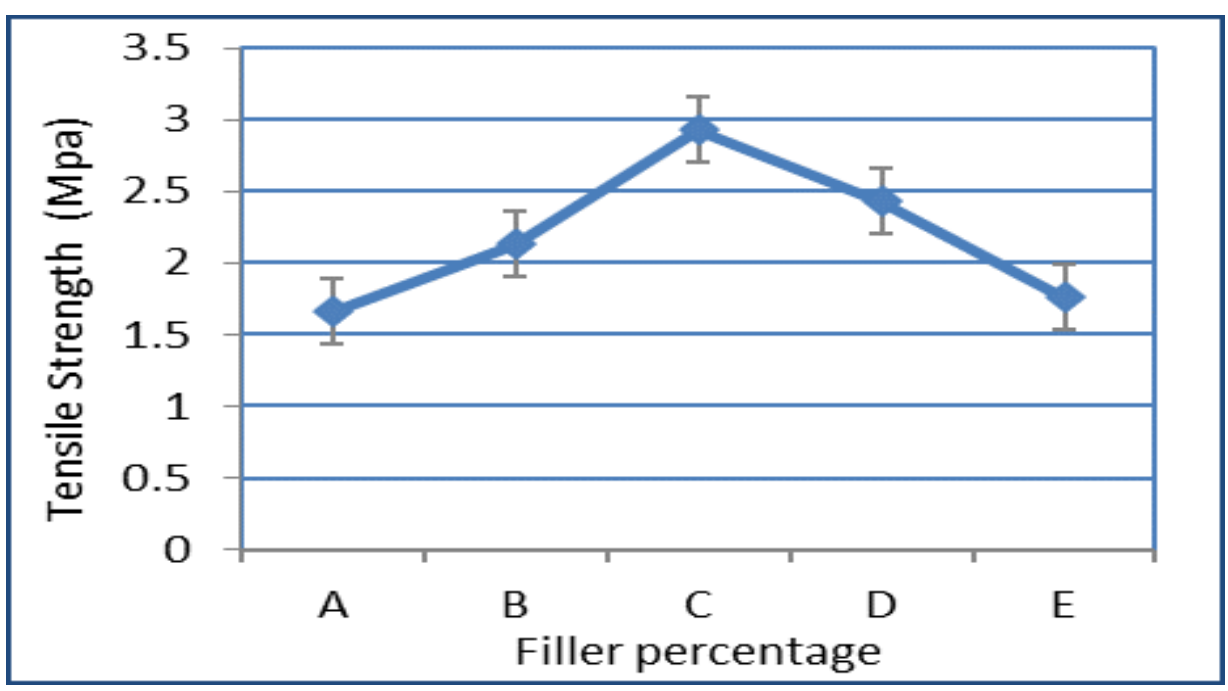

Figure 5: The elongation force of sample against different percentages of filler.

The above obtained results of the effect of adding ATH filler to the EPDM on the mechanical properties of the composite insulation can be explained in the light of the resulting increased rigidity of the composite insulation. This may be further investigated through more investigation on the microscopic structure using X-ray diffraction (XRD) and Transmission Electron Microscope (TEM) investigations. 


\section{CONCLUSION}

1) The changes of electrical and mechanical properties of EPDM by adding different percentage of ATH filler are investigated under various temperature and atmospheric conditions.

2) The dielectric strength of EPDM reached to $37 \mathrm{kV} / \mathrm{mm}$ by adding $30 \%$ of ATH under dry condition which means that the dielectric strength is improved by almost $23 \%$.

3) The tensile strength of EPDM reached to $2.93 \mathrm{MPa}$ with adding $20 \%$ of ATH filler which means that tensile strength is improved by almost $76 \%$.

4) All properties such as physical, mechanical and electrical have decreased at higher salinities and moisture.

5) ATH filler plays a vital role for the electrical properties of EPDM insulating material; breakdown voltage increases with the increase of the ATH filler up to 30\%. Therefore, it is recommended to add ATH filler at this percentage to obtain the optimum values of breakdown voltage.

\section{SOURCES OF FUNDING}

None.

\section{CONFLICT OF INTEREST}

None.

\section{ACKNOWLEDGMENT}

The authors wish to thank the staff of the High Voltage Laboratory, the Electrical Engineering Dept, Ain Shams University and the National Research Center, Polymers and Pigments Dept. where large portion of the samples preparation and experimental work were completed.

\section{REFERENCES}

[1] Jeffry Mackevich, et al, " Polymer Outdoor Insulating Materials Part I: Comparison of Porcelain and Polymer Electrical Insulation", IEEE Electrical Insulation Magazine Vol. 13, No. 3, 1997.

[2] J. F. Hall, "History and Bibliography of Polymeric Insulators for Outdoor Applications," IEEE Trans. Power Del., vol.8, no. 1, pp. 376-385, 1993.

[3] Y. Kurata, et al, "Evaluation of EPDM Rubber for High Voltage Insulator", IEEE, proceedings of 1995 conference on electrical insulation and dielectric Phenomena.1995.

[4] R. Raja Prabu, et al," Electrical Insulation Characteristics of Silicone and EPDM Polymeric Blends- Part I", IEEE Trans. Dielectrics and Electrical Insulation, Vol. 14, pp. 1207-1214, 2007.

[5] Isaías Ramírez, et al," Silicone Rubber and EPDM Micro Composites Filled with Silica and ATH", Annual Report Conference on Electrical Insulation and Dielectric Phenomena, IEEE, Cancun, Mexico 2011.

[6] M.S.M. RIZK, et al.” A Comparative Study of Polyester/Styrene with Inorganic Fillers under Different Testing Conditions" Conference Record of the 1992 IEEE International Symposium on Electrical Insulation, Baltimore, MD USA, June 7-10, 1992.

[7] N. N. Azmi, et al," Testing Standards Assessment for Silicone Rubber “, IEEE, International Symposium on Technology Management and Emerging Technologies, Bandung, Indonesia ,2014.

[8] A. Krivda, et al." Breakdown between Water Drops on Wet Polymer Surfaces", Annual Report Conference on Electrical Insulation and Dielectric Phenomena (Cat. No.01CH37225), IEEE, Kitchener, Ontario, Canada, 2001. 